\title{
Endo-Parasites of Apparently Healthy Wild Birds in Kaduna State, Nigeria
}

\author{
Assam, Assam ${ }^{1 *}, \mathrm{Abdu}$, Salamatu ${ }^{2}, \mathrm{Paul} \mathrm{Abdu}^{3}$ and Augustine, Ezealor ${ }^{4}$ \\ ${ }^{1}$ Department of Animal Science, Faculty of Agriculture and Forestry, Cross River University of \\ Technology (CRUTECH), Obubra, Nigeria. \\ ${ }^{2}$ Department of Collective Behavior, Max Planck Institute for Animal Behavior, Radolfzell, Germany. \\ ${ }^{3}$ Department of Veterinary Medicine, Faculty of Veterinary Medicine, Ahmadu Bello University, Zaria, \\ Nigeria. \\ ${ }^{4}$ Department of Biological Sciences, Faculty of Science, Micheal Okpara University of Agriculture, \\ Umudike, Nigeria.
}

\section{Authors' contributions}

This work was carried out in collaboration among all authors. Authors AA and AS designed the study. Authors AE and AS captured and identified the birds. Author AA performed the statistical analysis. Authors $A A$ and PA wrote the protocol and the first draft of the manuscript. All authors read and approved the final manuscript.

Article Information

DOI: $10.9734 / A R R B / 2020 / v 35 i 1230312$ Editor(s):

(1) Dr. Md. Aminur Rahman, Jashore University of Science and Technology, Bangladesh.

1) Ramazan llgün, Aksaray Universeviewers: (2) Krishna Pada Das, Mahadevananda Mahavidyalaya, India. (3) Nittin Dev Singh, GADVASU, India Complete Peer review History: http://www.sdiarticle4.com/review-history/58378

Original Research Article

Received 15 April 2020

Accepted 21 June 2020 Published 14 December 2020

ABSTRACT

Aims: Wildbirds interaction with poultry increases the likelihood of exchange of parasites between wild birds and poultry highlighting the need to understand wild bird endoparasites to reduce crossinfection at the wild bird-poultry interface. This study investigates the prevalence and diversity of endoparasites among wild birds in Kaduna State to provide baseline data on the wild birds' endoparasites which could be a source of infection to poultry.

Study Design: Wild birds in live wild bird markets, free-flying wild birds and semi-domesticated birds were the samples for endoparasites.

Place and Duration of Study: Birds were sampled in Kaduna State, Nigeria and the samples were analyzed at the helminthology laboratory of Ahmadu Bello University, Zaria between April 2012 and December 2012. 
Methodology: Wild birds faecal samples were examined for endoparasites by the simple flotation method.

Results: Of the 357 birds sampled, $36.4 \%$ were infected with at least one species of endoparasite. Charadriidae $(7.1 \%)$ and Meleagris gallopavo $(23.5 \%)$ had the lowest family and species prevalence respectively. Free flying, live poultry markets (LPM) and live wild bird markets (LWBM) birds had a prevalence of $39.1 \%, 37.2 \%$ and $34 \%$ respectively. The endoparasites identified were coccidia (30.5\%), Ascaridia (5.9\%), nematode larvae (0.8\%), Capillaria (0.6\%); Syngamus, Raillietinia and Trichuris $(0.3 \%$ for each). There was a significant difference between the prevalence $(p=0.00)$, mean intensities $(p=0.00)$ and abundance $(p=0.01)$ of coccidia and Ascaridia. The prevalence of multiple infections was $2.0 \%$ representing $5.4 \%$ of infected birds. The study is first to report in Kaduna State, Nigeria of Trichuris in Anas platyrhynchos and Raillietina in Laniarius barbarous.

Conclusion: Wild birds in Kaduna State, Nigeria harbours endoparasites of economic significance to poultry and there is the need for more study of these wild birds' endoparasites at the wild birdpoultry interface.

Keywords: Anas platyrhynchos; endoparasite; Kaduna State; Laniarius barbarous; Raillietina; Trichuris; wild bird.

\section{INTRODUCTION}

Wild birds are an essential component of an ecosystem and they interact with poultry, humans and other livestock with the likelihood of exchange of parasites between wild birds and livestock [1]. Parasites are abundant in wild birds with an individual bird likely to be infected by different parasites during their lifetime though reports of clinical disease due these parasites are usually rare in healthy individuals in the wild [2]. However, parasites usually cause severe distress and infections in captive wild birds, especially those kept under crowded and poor sanitary conditions [3].

In Nigeria, wild birds hunted for food and aesthetic reason are sold in live wild bird markets (LWBM) and raised in captivity thus increasing the stress on the birds and the wild bird-human interaction [4]. Increased urbanization leading to encroachment into wildlife habitats has increased wild birds' dependence on human activities for food, as they visit poultry and newly tilled farms to feed on spilt poultry feed/seeds or other livestock materials within farms [5].

The understanding of the endoparasites infecting wild birds in Nigeria is fragmentary due to inadequate baseline information about the host species with a rudimentary knowledge of the wild bird life-history traits [6]. This has led to the extrapolation from other species especially poultry in a bid to understand the relationship between wild birds and their endoparasites. There is a need to identify the endoparasites in a wild bird to reduce cross-infection at the wild bird-livestock interface.

This study investigated the prevalence and diversity of endoparasites among wild birds in three epidemiologic units through morphologic identification and evaluated the patterns of infection.

\section{MATERIALS AND METHODS}

\subsection{Study Area}

The study was carried out in Kaduna State, located in North-Western Nigeria between latitude $8^{\circ} 45^{\prime \prime}-11^{\circ} 30^{\prime \prime}$ North and longitude $6^{\circ} 11^{\prime \prime}$ - $9^{\circ}$ East [7]. It shares a boundary with Kastina, Kano, Plateau, Niger, Zamfara, Bauchi, Nassarawa and FCT and has 23 local government areas that are inhabited by ethnic groups including Hausa, Fulani, Kaje and Kataf amongst others. Kaduna State has a population of 6 million people and 2,821,092 poultry of which $90 \%$ is local poultry raised extensively [7].

The annual temperature is $34^{\circ} \mathrm{C}$ with hottest months being March-April $\left(40^{\circ} \mathrm{C}\right)$ and the coolest period $\left(13.2^{\circ} \mathrm{C}\right)$ being December during severe harmattan. Rainfall varies between $1,000 \mathrm{~mm}$ and $1,500 \mathrm{~mm}$ and the rainy season lasts $100-$ 150 days (Mid April - ending of October). The dry season occurs between October and April [7]. Kaduna State has a land structure of undulating Plateau with major rivers including River Kaduna, River Wonderful in Kafanchan, 
River Kagom, River Gurara and Galma [7]. The vegetation varies from the Guinea Savannah in the south to the Sudan Savannah in the North [7].

\subsection{Sampling Technique}

Wild bird in LWBMs, free-flying and semidomesticated birds from live poultry markets (LPMs) were sampled during the study. Four sampling locations were chosen based on poultry density, presence of LWBMs and LPMs; water bodies.

The sample size for the study was not predetermined due to lack of information on the prevalence rate of ectoparasites in Kaduna State and the inability to estimate the population of wild birds in Kaduna State. A targeted sampling was done. All birds sampled (except roasting birds) were marked using a permanent marker to avoid multiple sampling of the same bird.

\subsection{Sampling Units}

Wild birds were sampled from three epidemiologic units namely live wild bird markets (LWBMs), free-flying wild birds and live poultry markets (LPMs).

\subsubsection{Live wild bird market}

Live wild birds in Kaduna LWBMs were sampled after live wild bird sellers in Kaduna LWBMs were approached and consent obtained for participation in the study.

\subsubsection{Free flying wild birds}

Free flying birds are wild birds that were not in captivity. The birds were captured by mist nets, hunting and use of other traps. Hunters gave consent for hunted birds to be sampled. For freeflying wild birds roosting on trees, faecal samples were collected by the use of a white paper. Free flying wild birds were sampled from Kaduna, Samaru, Anchau, Karoye and Sabon Gari.

\subsubsection{Live poultry markets}

Two semi-domesticated species - guinea fowls and mallard ducks were identified due to their arboreal nature and likelihood of interacting with wild birds especially migratory birds and local poultry in human habitats. Live mallards and guinea fowls were sampled from Anchau LPM after obtaining consent from sellers to sample birds.

\subsection{Identification of Wild Bird}

Wild birds roasting on trees whose faecal samples were collected were also identified using a pair of binoculars with magnification $7 x$ 50. All birds were visually identified with the aid of a field guide by Borrow and Demey [8] and physically examined before sampling.

\subsection{Faecal Sample Collection}

Fresh faecal samples were collected from identified wild birds using swab sticks into labelled tubes. Faecal droppings of roasting wild birds were also collected after identification of the bird species.

All faecal samples were individually collected and stored in insulated clean tubes which were labelled with bird species, field number and date. The samples were then preserved in a cooler before being transported to the laboratory and stored in the fridge at $+4^{\circ} \mathrm{C}$ until analyzed.

\subsection{Identification of Endoparasites in Faecal Sample}

The faecal samples collected were examined for helminthes eggs, coccidia oocytes and other intestinal parasites by the simple flotation method. Briefly, a sodium chloride-sucrose solution was used as the washing and diluting medium which concentrates the parasites on the surface which were collected on microscope cover-slips and viewed under a microscope in the Helminthology Laboratory of the Department of Veterinary Parasitology and Entomology, Ahmadu Bello University Zaria, Nigeria. Slides were microscopically screened at 100X and 400X magnifications and parasites are seen were identified by their morphometric characteristics and documented by photography [9].

\subsection{Data Analysis}

The positive bird was defined as any wild bird with at least one endo-parasite. Prevalence, mean intensity and mean abundance values were analysed using Quantitative Parasitology $3.0[10]$. 
The differences in prevalence between endo-parasites, was determined using chi square test. The difference in mean intensity and abundance between parasites was determined using t-test. The median intensities were compared using Mood's median test [10]. Confidence intervals for prevalence and intensity were computed using Sterne's exact method, and bootstrapping (with 2,000 repetitions), respectively, using the computer program Quantitative Parasitology 3.0 [11].

Prevalence between and within families, species, epidemiologic units and sampling sites, were compared by the chi-square test with $p$ values $\leq$ 0.05 considered significant. Association of endo-parasite and other parameters were analyzed using cross-tabulations with Statistical Package for Social Sciences (SPSS) version 17.

\section{RESULTS AND DISCUSSION}

\subsection{Results}

Of the 357 birds sampled in this survey, $36.4 \%$ $(130 / 357)$ were infected with at least one species of internal parasites. The parasites were coccidia oocytes, nematode larvae, Ascaridia, Syngamus, Trichuris and Raillietinia and Capillaria eggs (Plate 1).

The prevalence for Coccidia oocytes was $30.5 \%$ $(109 / 357)$ at $95 \%$ confidence limits (CL) of 25.1 $35.9 \%$ with a mean intensity and abundance of $12.24(95 \% \mathrm{CL}$ of 11.41 - 13.06) and $3.70(95 \%$ of 2.99 - 4.45) respectively. Ascaridia eggs prevalence was $5.9 \%$ (21/357) with CL of 4.8 1.1 at $95 \%$ confidence interval with a mean intensity and abundance of 10.5 (95\% CL of 10.00 - 11.50) and 0.75 (95\% CL 0.43 - 1.07). There was a significant difference between the prevalence $(p=0.00)$, mean intensities $(p=0.00)$ and abundance $(p=0.01)$ of coccidia oocytes and Ascaridia eggs. Generally, mild and moderate coccidian oocytes infection prevalence was $24.9 \% \quad(89 / 357)$ and $6.2 \% \quad(22 / 357)$ respectively although among coccidia oocytes infected birds, $81.7 \%$ (89/109) were mildly infected with $20.2 \% \quad(22 / 109)$ been moderately infected. The prevalence of other endoparasites encountered in during the study was $0.8 \%(3 / 357)$ for nematode larvae; $0.3 \%$ $(1 / 357)$ for Syngamus, Raillietinia and Trichuris eggs respectively and $0.6 \%$ (2/357) for Capillaria.
About $77.8 \%$ (28/36) families and $67.2 \%$ (41/61) species were infected with endoparasites, with Meleagris gallopavo had the lowest species prevalence rate of $23.5 \%(4 / 17)$ (Table 1).

Twenty three six had coccidia oocytes infection with prevalence ranging from 9.1\% (1/11) for Malaconotidae to $100 \%$ for Acciptridae. Similarly, 37 species were infected with coccidia oocytes with a prevalence range of $12.5 \%$ to $100 \%$. However, 25\% (9/36) of sampled families had Ascaridia infection with $11.1 \%(1 / 9)$ of infected families having moderate Ascaridia eggs infection (Table 2). Only $6.1 \%(2 / 33)$ of studied families had Capillaria eggs infection, with prevalence rates of $3.3 \%$ (1/30) for Numididae (Table 3). Nematode larvae were reported in Vanellus spinosus and Amaurornis flavirostra with species prevalence rates of $50 \%(1 / 2)$ and $10 \%(1 / 10)$ respectively (Table 3$)$. Trichuris eggs were observed only in Anas platyrhynchos of the Anatidae family while Laniarius barbarus were infected with Raillietina (Table 3). Brown Babbler (Turdoides plebejus) was the only species infected with Syngamus.

The prevalence of multiple endoparasite infection in the study was $2.0 \%$ (7/375) representing $5.4 \%$ (7/130) of infected birds. However, among birds with multiple endoparasite infection, $57.1 \%(4 / 7)$ had mild Ascaridia eggs/mild coccidia oocytes infection, with $14.3 \%(1 / 7)$ having mild coccidia oocytes /moderate Ascaridia eggs and $28.6 \%$ (2/7) having moderate coccidia oocytes/moderate Ascaridia eggs infections.

Endoparasite prevalence in free flying birds was $39.1 \%(79 / 202)$ while the prevalence for LBM and LWBM were $37.2 \%(16 / 43)$ and $34 \%$ (35/103) respectively. Coccidia oocyts prevalence in free flying birds was $33.2 \%$ $(67 / 202)$ at $95 \%$ confidence limits of $24.4 \%$ $40.3 \%$ with mean intensity and abundance of 12.09 (95\% CL of 10.93 - 13.26) and $3.85(95 \%$ CL of 2.96 - 4.89) respectively. The LBM and LWBM coccidia oocyts prevalence were $25.6 \%$ $(11 / 43)$ at $95 \% \mathrm{CL}$ of $14.6 \%-40.6 \%$ and 30.1 $(31 / 103)$ at $95 \%$ CL of $21.8 \%-39.8 \%$ respectively.

Among the wild bird's infected coccidia oocytes, $63.2 \%(55 / 87)$ free flying birds had mild coccidia infection together with $11.5 \%(10 / 87)$ and $25.3 \%$ $(22 / 87)$ of LPM and LWBM birds. Moderate coccidia infection was $54.2 \%(12 / 22)$ for free flying $40.9 \%(9 / 22)$ for LWBM birds and $4.5 \%$ $(1 / 22)$ for LPM birds. 
Table 1. Prevalence of endoparasites among wild birds in Kaduna State, Nigeria ( $P=\mathbf{0 . 0 0})$

\begin{tabular}{|c|c|c|}
\hline Infected Family/Species & $P$ (No. infected/sampled) & Coccidia oocyts \\
\hline Acciptridae & $100 \%(2 / 2)$ & $100 \%(1 / 1)$ \\
\hline Elanus caeruleus & $100.0 \%(1 / 1)$ & $100.0 \%(1 / 1)$ \\
\hline Pandion haliaetus & $100.0 \%(1 / 1)$ & $100.0 \%(1 / 1)$ \\
\hline Anatidae & $26.9 \%(7 / 26)$ & $15.4 \%(4 / 26)$ \\
\hline Barn geese & $23.1 \%(3 / 13)$ & $15.4 \%(2 / 13)$ \\
\hline Anas platyrhynchos & $30.8 \%(4 / 13)$ & $15.4 \%(2 / 13)$ \\
\hline Ardeidae & $30.8 \%(4 / 13)$ & $30.8(4 / 13)$ \\
\hline Ardea cinerea & $33.35(1 / 3)$ & $33.3 \%(1 / 3)$ \\
\hline Bubulcus ibis & $33.3 \%(1 / 3)$ & $33.3 \%(1 / 3)$ \\
\hline Egretta alba & $33.3 \%(1 / 3)$ & $33.3 \%(1 / 3)$ \\
\hline Ardeola ralloides & $25 \%(1 / 4)$ & $25 \%(1 / 4)$ \\
\hline Charadriidae & $7.1 \%(1 / 14)$ & $35.7 \%(5 / 14)$ \\
\hline Vanellus spinosus & $50 \%(4 / 8)$ & $37.5 \%(3 / 8)$ \\
\hline Vanellus tectus & $66.7 \%(2 / 3)$ & $66.7 \%(2 / 3)$ \\
\hline Ciconiidae & $27.3 \%(9 / 33)$ & $27.3 \%(9 / 33)$ \\
\hline Ciconia ciconia & $27.3 \%(9 / 33)$ & $27.3 \%(9 / 33)$ \\
\hline Columbidae & $38.5 \%(15 / 39)$ & $33.3 \%(13 / 39)$ \\
\hline Columba livia & $50 \%(2 / 4)$ & $50 \%(2 / 4)$ \\
\hline Streptopelia senegalensis & $37.8 \%(6 / 16)$ & $37.8(6 / 16)$ \\
\hline Streptopelia vinacea & $50 \%(2 / 4)$ & $50 \%(2 / 3)$ \\
\hline Streptopelia capicola & $40 \%(2 / 5)$ & $20.0 \%(1 / 5)$ \\
\hline Streptopelia semitorquata & $50 \%(2 / 4)$ & $50.0 \%(2 / 4)$ \\
\hline Corvidae & $100 \%(2 / 2)$ & $100.0 \%(2 / 2)$ \\
\hline Corvus albus & $100.0 \%(1 / 1)$ & $100.0 \%(1 / 1)$ \\
\hline Ptilostomus afer & $100 \%(1 / 1)$ & $100 \%(1 / 1)$ \\
\hline Cuculidae & $100 \%(1 / 1)$ & $100(1 / 1)$ \\
\hline Centropus senegalensis & $100 \%(1 / 1)$ & $100(1 / 1)$ \\
\hline Dicruridae & $100 \%(1 / 1)$ & $100.0 \%(1 / 1)$ \\
\hline Dicrurus adsimilis & $100 \%(1 / 1)$ & $100.0 \%(1 / 1)$ \\
\hline Gruidae & $62.5 \%(5 / 8)$ & $62.5 \%(5 / 8)$ \\
\hline Balearica pavonina & $62.5 \%(5 / 8)$ & $62.5 \%(5 / 8)$ \\
\hline Hirundinidae & $25 \%(2 / 8)$ & $12.5 \%(1 / 8)$ \\
\hline Hirundo aethiopica & $25 \%(2 / 8)$ & $12.5 \%(1 / 8)$ \\
\hline Indicatoriidae & $100 \%(1 / 1)$ & $100 \%(1 / 1)$ \\
\hline Honey guide & $100 \%(1 / 1)$ & $100 \%(1 / 1)$ \\
\hline Jacanidae & $33.3 \%(1 / 3)$ & $33.3 \%(1 / 3)$ \\
\hline Actophilornis africanus & $33.3 \%(1 / 3)$ & $33.3 \%(1 / 3)$ \\
\hline Malaconotidae & $15.4 \%(2 / 11)$ & $9.1 \%(1 / 11)$ \\
\hline Tchagra minutes & $100 \%(1 / 1)$ & $100 \%(1 / 1)$ \\
\hline Laniarius barbarous & $33.3 \%(3 / 9)$ & $22.2 \%(2 / 9)$ \\
\hline Melagrididae & $17.6 \%(3 / 17)$ & $17.6 \%(3 / 17)$ \\
\hline Meleagris gallopavo & $23.5 \%(4 / 17)$ & $17.6 \%(3 / 17)$ \\
\hline Musophagidae & $66.7 \%(2 / 3)$ & $66.7 \%(2 / 3)$ \\
\hline Crinifer piscator & $66.7 \%(2 / 3)$ & $66.7 \%(2 / 3)$ \\
\hline Nectariniidae & $22.2 \%(2 / 9)$ & $22.2 \%(2 / 9)$ \\
\hline Chalcomitra senegalensis & $28.6 \%(2 / 7)$ & $28.6 \%(2 / 7)$ \\
\hline Numididae & $40 \%(12 / 30)$ & $30 \%(9 / 30)$ \\
\hline Numida meleagris & $40 \%(12 / 30)$ & $30 \%(9 / 30)$ \\
\hline Phasianidae & $39.3 \%(22 / 56)$ & $35.7 \%(20 / 56)$ \\
\hline Francolinus bicalcaratus & $41.5 \%(22 / 53)$ & $35.8 \%(19 / 53)$ \\
\hline Pavo cristatus & $33.3 \%(1 / 3)$ & $33.3 \%(1 / 3)$ \\
\hline Ploecidae & $66.7 \%(2 / 3)$ & $33.3 \%(1 / 3)$ \\
\hline Ploceus cucullatus & $66.7 \%(2 / 3)$ & $33.3 \%(1 / 3)$ \\
\hline
\end{tabular}




\begin{tabular}{|c|c|c|}
\hline Infected Family/Species & $P$ (No. infected/sampled) & Coccidia oocyts \\
\hline Psittacidae & $100 \%(1 / 1)$ & $100 \%(1 / 1)$ \\
\hline African grey & $100 \%(1 / 1)$ & $100 \%(1 / 1)$ \\
\hline Pynonotidae & $52.6 \%(10 / 19)$ & $52.6 \%(10 / 19)$ \\
\hline Pychonotus barbatus & $52.6 \%(10 / 19)$ & $52.6 \%(10 / 19)$ \\
\hline Rallidae & $57.9 \%(11 / 19)$ & $36.8 \%(7 / 19)$ \\
\hline Amaurornis flavirostra & $66.7 \%(6 / 9)$ & $33.3 \%(3 / 9)$ \\
\hline Porphyrio porphyrio & $55.6 \%(5 / 9)$ & $44.4 \%(4 / 9)$ \\
\hline Recurvirostridae & $25 \%(1 / 4)$ & $25 \%(1 / 4)$ \\
\hline Himantopus himantopus & $25 \%(1 / 4)$ & $25 \%(1 / 4)$ \\
\hline Rostratulidae & $100 \%(1 / 1)$ & $0 \%$ \\
\hline Rostratula benghalensis & $100 \%(1 / 1)$ & $0 \%$ \\
\hline Slyviidae & $100 \%(1 / 1)$ & $100 \%(1 / 1)$ \\
\hline Slyvia melanocephala & $100 \%(1 / 1)$ & $100 \%(1 / 1)$ \\
\hline Timaliidae & $50 \%(1 / 2)$ & $50 \%(1 / 2)$ \\
\hline Turdoides plebejus & $50 \%(1 / 2)$ & $50 \%(1 / 2)$ \\
\hline Turdidae & $33.3 \%(2 / 6)$ & $33.3 \%(2 / 6)$ \\
\hline Turdus pelios & $33.3 \%(2 / 6)$ & $33.3 \%(2 / 6)$ \\
\hline Total & $36.4 \%(130 / 357)$ & $30.5 \%(109 / 357)$ \\
\hline
\end{tabular}

Table 2. Prevalence of Ascarida eggs among wild birds in Kaduna State, Nigeria $\left(p=0.00 ; X^{2}=\right.$ 389.86)

\begin{tabular}{ll}
\hline Infected Family/Species & Ascaridia eggs \\
\hline Anatidae & $\mathbf{7 . 7 \% ( 2 / 2 6 )}$ \\
Barn geese & $7.7 \%(1 / 13)$ \\
Anas platyrhynchos & $7.7 \%(1 / 13)$ \\
Ardeidae & $\mathbf{1 6 . 7 \% ( 1 / 6 )}$ \\
Ardea cinerea & $33.3 \%(1 / 3)$ \\
Columbidae & $\mathbf{6 . 9 \% ( 2 / 2 9 )}$ \\
Streptopelia vinacea & $33.3 \%(1 / 3)$ \\
Streptopelia capicola & $20 \%(1 / 5)$ \\
Hirundinidae & $\mathbf{1 2 . 5 \% ( 1 / 8 )}$ \\
Hirundo aethiopica & $12.5 \%(1 / 8)$ \\
Melagrididae & $\mathbf{1 1 . 8 \% ( 2 / 1 7 )}$ \\
Meleagris gallopavo & $11.8 \%(2 / 17)$ \\
Numididae & $\mathbf{1 0 \% ( 3 / 3 0 )}$ \\
Numida meleagris & $10 \%(3 / 30)$ \\
Phasianidae & $\mathbf{1 0 . 2 \% ( 5 / 5 0 )}$ \\
Francolinus bicalcaratus & $8.7 \%(4 / 46)$ \\
Pavo cristatus & $33.3 \%(1 / 3)$ \\
Ploecidae & $\mathbf{5 0 \% ( 1 / 2 )}$ \\
Ploceus cucullatus & $100 \%(1 / 1)$ \\
Pynonotidae & $\mathbf{9 . 1}(1 / 11)$ \\
Pychonotus barbatus & $9.1(1 / 11)$ \\
Rallidae & $\mathbf{1 5 . 8 ( 3 / 1 9 )}$ \\
Amaurornis flavirostra & $11.1 \%(1 / 9)$ \\
Porphyrio porphyrio & $22.2 \%(2 / 9)$ \\
Total & $\mathbf{7 . 1 \% ( 2 0 / 2 8 1 )}$ \\
\hline
\end{tabular}

The Ascaridia eggs prevalence in free flying birds at $95 \%$ with $\mathrm{CL}$ of $3.4 \%-1.2 \%$ was $5.0 \%$ $(10 / 202)$ with a mean intensity and abundance of 11.11 (at $95 \% \mathrm{CL}$ of $10.00-13.33$ ) and 0.74 (at $95 \% \mathrm{CL}$ of $0.30-1.26)$ respectively. Ascaridia eggs prevalence in LBM and LWBM were $9.3 \%$ $(4 / 43)$ at $95 \% \mathrm{CL}$ of $2.6-22.1$ and $6.8 \%(7 / 103)$ at $95 \% \mathrm{CL}$ of $3.2-13.5$ respectively with mean abundance of 0.93 (at $95 \% \mathrm{CL}$ of $0.23-1.86$ ) and 0.68 (at $95 \% \mathrm{CL}$ of $0.19-1.17$ ) respectively. Capillaria and Syngamus were observed only in free flying with prevalence of $0.7 \%$ $(1 / 202)$. Capillaria prevalence in LPMs was $2.3 \%$ $(1 / 43)$. 


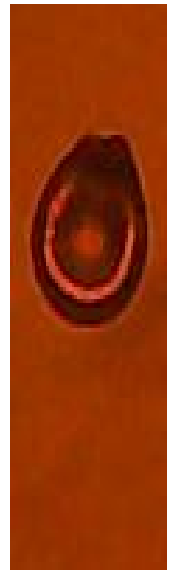

(a)

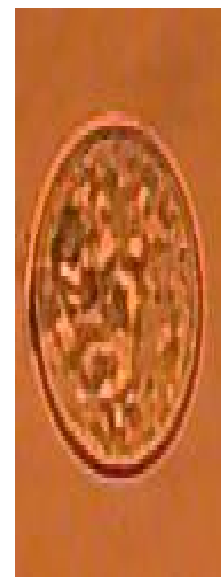

(b)

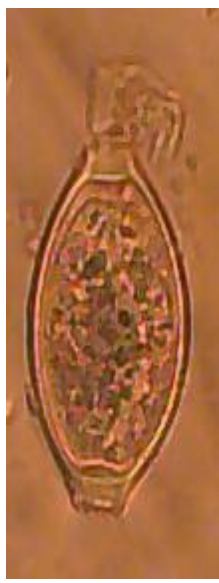

(c)

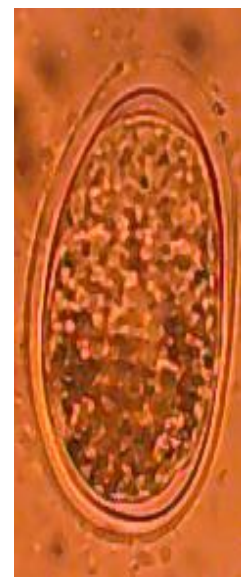

(d)

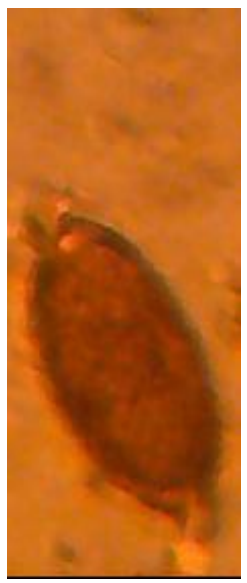

(e)

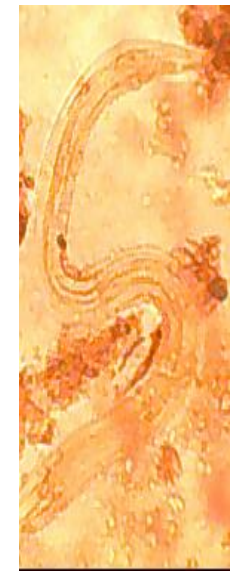

(f)

Plate 1. Endoparasites of wild birds in Kaduna State, Nigeria. (a) Coccidia oocyte from the grey heron. (b) Coccidia oocyte from laughing dove. (c) Tricuris eggs from mallard duck. (d) Ascaridia eggs from purple swamphen. (e) Capillaria eggs from Allen ganulle. (f) Nematode larvae from spur-winged lapwing

Table 3. Prevalence of Nematode larvae, Capillaria, Trichuris and Raillietina among wild birds in Kaduna State, Nigeria $\left(p=0.00 ; X^{2}=389.86\right)$

\begin{tabular}{lllll}
\hline Infected Family/Species & Capilaria & Trichuris & Nemadode larvae & Raillietina \\
\hline Anatidae & $-\dagger$ & $3.8 \%(1 / 26)$ & - & - \\
Anas platyrhynchos & - & $7.7 \%(1 / 13)$ & - & - \\
Charadriidae & - & - & $20 \%(1 / 5)$ & - \\
Vanellus spinosus & - & - & $50 \%(1 / 2)$ & - \\
Malaconotidae & - & - & - & $25 \%(1 / 4) ;$ \\
Laniarius barbarous & - & - & - & $50 \%(1 / 2)$ \\
Numididae & $3.3 \%(1 / 30)$ & - & - & - \\
Numida meleagris & $3.3 \%(1 / 30)$ & - & - & - \\
Rallidae & $5.3 \%(1 / 19)$ & - & $5.3 \% 1 / 19) ;$ & - \\
Amaurornis flavirostra & $11.1 \%(1 / 9)$ & - & $11.1 \%(1 / 9)$ & - \\
Rostratulidae & - & - & $100 \%(1 / 1)$ & - \\
Rostratula benghalensis & - & - & $100 \%(1 / 1)$ & - \\
& & $\dagger=$ Negative
\end{tabular}

Endoparasite prevalence within sampling sites were $38.4 \%(28 / 73)$ in Anchau, 33.6\% (36/107) in Kaduna, 38\% (62/160) in Samaru; $50 \%(2 / 4)$ in Koraye and $33.3 \%(2 / 6)$ in Sabon Gari. However, between locations, endoparasite prevalence was $21.5 \%(28 / 130)$ in Anchau, $27.7 \%(36 / 130)$ in Kaduna, $47.7 \%(62 / 130)$ in Samaru; and $1.5 \%(2 / 130)$ in Sabon Gari and Koraye.

The coccidia oocyts prevalence in Anchau and Kaduna were $28.8 \%(21 / 73)$ at $95 \% \mathrm{CL}$ of $19 \%$ $40.4 \%$ and $29.0 \%(31 / 107)$ at $95 \%$ CL of $20.9 \%$ - 38.3\%. However, their mean intensities and abundance were 11.4 (at $95 \% \mathrm{CL}$ of $10-12.86$ ) and 3.29 (at $95 \% \mathrm{CL}$ of $2.1-4.7$ ) and 12.9 (at $95 \% \mathrm{CL}$ of $11.3-14.2$ ) and 3.74 (at $95 \% \mathrm{CL}$ of
2.7-5.0) respectively. Coccidia oocyts prevalence in Samaru was $33.5 \%(53 / 158)$ at $95 \% \mathrm{CL}$ of $23 \%-42.3 \%$ and with mean intensities and abundance of 11.7 (at 95\% CL of 10.3 12.8) and 3.74 (at $95 \%$ CL of 2.6-5.0) respectively.

The Ascaridia eggs prevalence were 9.6\% (7/73) in Anchau, $7.5 \%$ (8/107) in Kaduna and $3.4 \%$ $(6 / 158)$ in Samaru. However, among birds infected with Ascaridia, 33.3\% (7/21) were from Anchau, $38.1 \%$ (8/21) from Kaduna and $28.6 \%$ (5/21) from Samaru. Although, capillaria eggs were observed in Anchau and Samaru, 1.9\% $(3 / 158)$ and $0.6(1 / 158)$ of the birds in Samaru were infected with nematode larvae and Raillietina respectively. Also, $1.4 \%(1 / 73)$ of the 
birds sampled in Anchau was infected with Trichuris eggs.

\subsection{Discussion}

The study revealed that five types of endoparasites were prevalent in wild birds in Kaduna State. The parasites were a protozoan (coccidian), three nematodes (Ascaridia, Trichuris and Capillaria) and a cestode (Raillietina). Most studies on endoparasites of wild birds investigated a single species of birds and the prevalence varies with most reporting a higher prevalence than was observed in the present study $[4,12]$.

The study further revealed that though wild birds were infected with coccidia and Ascaridia, the infection was mild. Among the endoparasites found, coccidia was more abundant but with a lower prevalence compared to previous studies [13]. However, the absence of clinical coccidiosis in these wild birds is probably due to repeated exposures to a few oocytes, which resulted in the development of immunity [14].

The coccidia infection in these wild birds may negatively affect their physical appearance by reducing the signalling value of morphological traits, and behaviour $[15,16,17,18]$. Likewise, due to the presumed strict host specificity of the avian species of coccidia, these coccidias might not be a threat to unrelated poultry species, though the mixing of wild birds of different species should be discouraged [19]. Conversely, there are reports of possible infection of wild birds such as Passerines with coccidia which might subsequently serve as a potential source of infection to poultry [12].

The families with high endoparasite prevalence are members of the orders Anseriformes and Galliformes which have the highest reported species of coccidia and other endoparasites [19]. These birds are also closely related to poultry species implying the increased likelihood of cross-infectioncross-infection from poultry to wild birds and vice-versa.

This is the first report of Trichuris egg in Mallard duck in Nigeria. The duck is likely to have been infected when foraging in areas contaminated with Trichuris infected human or dog faeces. However, failure to identify the Trichus species is a limitation of the study. This finding might either an indication of active infection of the duck by Trichuris or mere passage of the eggs through the duck gut after ingestion since ducks are not the definitive host of Trichuris [9]. However, an active infection with eggs producing Trichuris in duck implies adaptation of Trichuris in ducks, a new host which is worrisome with the possible public health consequence [20].

The study revealed the prevalence of multiple infection contrary to previous studies within the same study area involving francolins, weaver birds and doves $[4,21,13]$. The difference in prevalence is likely due to previous work determining endoparasite prevalence based on the presence of the parasite unlike the current study in which is based on the presence of eggs and oocytes. However, the amount of eggs or oocytes produced depends on the developmental stage of the parasites, the interaction of the different parasites within a host and the fecundity of the parasite [17]. Wild birds with multiple infections are likely to experience increase immune system activation with resultant increased production of free radicals which significantly affects the wild birds', immunity against and resistance to infection [22,23].

The high intensity and abundance of coccidia in LWBM might be due to confinement of birds in cages resulting in continuous exposure to the coccidia oocyte though the development of resistance by the birds limits the infection. The continuous exposure to coccidia oocyte results in a chronic low-grade infection which stimulates the immune system resulting in increased blood bactericidal activity with high WBC concentration [24].

The study further revealed that birds from LPM are more likely to be infected with Ascaridia than free flying and LWBM birds. This is probably because though LPM and LWBM birds are confined resulting in exposure from infected wild birds and contaminated pens. LWBM birds are usually administered anti-helminthics due to their high financial value unlike LPM birds. However, free flying birds which are not confined are spared from re-infection associated with contaminated confined pens [17].

The low Capillaria prevalence in this study compared to other studies is likely due to the very low-intensity infections and low fecundity of Capillaria with a resultant underestimation of Capillaria true prevalence [19]. However, coinfections with multiple Capillarid species may be missed as Capillarid species cannot be identified by egg morphology [19]. 
The high endoparasite prevalence in Samaru might be due to high density of backyard poultry in Samaru with poor biosecurity practices which increase wild bird-poultry interaction with wild bird infection. Similarly, other anthropogenic activities such as farming with the use of unprocessed poultry manure as fertilizers are likely to increase wild bird endoparasitic infection in Samaru.

\section{CONCLUSION}

This study confirms that wild birds in Kaduna state are infected with endoparasites and increase in anthropogenic activities is likely to alter the wild bird-endoparasite interaction. Coccidia are the most prevalent endoparasite of wild birds in Kadunia State. The study provides baseline data on wild bird endoparasites and their prevalence within free flying, LWBMs and LPMs in Kaduna State, Nigeria. It also highlights the need for more study of endoparasites of wild birds and their interaction at the wild bird-poultry interface Nigeria.

\section{ACKNOWLEDGEMENT}

We also appreciate the World Bank - STEP-B project for part sponsorship through the Nigerian Innovators of Tomorrow (IOT) research grant. Acknowledge the assistance of Musa, L., Dahiru, J., Ahmadu, A., Kyang, C., Uti, E., Abdul, R., Happi, U., Cyril, M. and all the wild bird sellers during this work.

\section{CONSENT}

As per international standard written consent has been collected and preserved by the authors.

\section{ETHICAL APPROVAL}

As per international standard written ethical permission has been collected and preserved by the author(s).

\section{COMPETING INTERESTS}

Authors have declared that no competing interests exist.

\section{REFERENCES}

1. Karesh WB, Cook RA, Gilbert M, Newcomb J. Implications of wildlife trade on the movement of avian influenza and other infectious diseases. Journal of Wildlife Diseases. 2007;43:S55-59.

2. Olsen $\mathrm{GH}$, Orosz SE. Manual of Avian Medicine. Mosby, Inc. St. Louis, MO. 2000;622:305.

3. Barnes HJ. Parasites. In: Clinical Avian Medicine and Surgery. Harrison, G.J. and Harrison L.R., 306 Eds. W.B. Saunders Company, Philadelphia, PA. 1986;472485.

4. Adang KL, Oniye SJ, Ezealor AU, Abdu PA, Ajanusi OJ, Yoriyo KP. Ectoparasites and Gastro-Intestinal Helminths of BlackBilled Wood Dove (Turtur abyssinicus) and Vinaceous Dove (Streptopelia vinacea) Hartlaub and Finsch 1870 in Zaria, Nigeria. The Pacific Journal of Science and Technology. 2009;10(2):850-856.

5. Rowan MK. The Doves, Parrots, Louries and Cuckoos of Southern Africa. Academic Press: London, UK. 1983;429.

6. Zera AJ, Harshman LG. The physiology of life history trade-offs in animals. Annual Review of Ecology and Systematics. 2001;32:95.

7. RIM Report. Nigerian Livestock Reserve Resource Inventory \& Management Report, Federal Department of Livestock and Pest Control Services. 1993;1(4).

8. Borrow N, Demey R. A field guide to the birds of Western Africa. A \& C Black Publishers Ltd. London, UK. 2008;511.

9. Soulsby EJL. Helminths, Arthropods and Protozoa of Domestic Animal ( $7^{\text {th }}$ Edition.), Williams and Wilkins, Baltimore MD. 1982;367-703.

10. Rósza L, Reiczigel J, Majoros G. Quantifying parasites in samples of hosts. Journal of Parasitology. 2000;86:228-232.

11. Reiczigel J, Rózsa L. Quantitative parasitology 3.0. Budapest, Hungary; 2005.

12. Ibrahim UIA, Mbaya W, Geidam YA, Geidam AM. Endoparasites and associated worm burden of captive and free-living ostriches (Struthio camelus) in the semi-arid region of North Eastern Nigeria. International Journal of Poultry Science. 2006;5(12):1128-1132.

13. Oniye SJ, Adebote DA, Nfor NB. Survey of Eimeria oocyts of guinea fowl (Numida meleagris galeata) in Zaria, Nigeria. Journal of Pest, Disease and Vector Management. 2000;4:265-267.

14. Yabsley ML. Emeria. In: Parasitic Diseases of Wild Birds. Edited by Atkinson, C. T., Thomas, N. J. and Hunter, 
D. B. 1st Ed. Wiley-Blackwell, lowa, USA; 2008a.

15. Aguilar TM, Maia R, Santos ESA, Macedo. $\mathrm{RH}$. Parasite levels in blue-black grassquits correlate with male displays but not female mate preference. Behavioral Ecology. 2008;19:292-301.

16. Baeta R, Faivre B, Motreuil S, Gaillard M, Moreau J. Carotenoid trade-off between parasitic resistance and sexual display: An experimental study in the blackbird (Turdus merula). Proceedings of the Royal Society of London, Series B. 2008a; 275:427-434.

17. Mougeot F, Pérez-Rodríguez L, Sumozas $\mathrm{N}$, Terraube J. Parasites, condition, immune responsiveness and carotenoidbased ornamentation in male red-legged partridge (Alectoris rufa). Journal of Avian Biology. 2009;40:67-74.

18. Dolnik OV, Hoi $H$. Honest signalling, dominance hierarchies and body condition in House Sparrows Passer domesticus (Aves: Passeriformes) during acute coccidiosis. Biological Journal of the Linnean Society. 2010;99:718-726.

19. Yabsley ML. Capillarid Nematodes. In: Parasitic Diseases of Wild Birds. Edited by Atkinson, C. T., Thomas, N. J. and Hunter, D. B. $1^{\text {st }}$ Ed. Wiley-Blackwell, lowa, USA; 2008b.
20. Ahmed A, Oniye SJ, Nock IH. Intestinal parasitosis in relation to growth and academic performance of students in Katsina State, Nigeria. Journal of Tropical Biosciences. 2003;3:42-47.

21. Mbinkar DL, Oniye SJ, Ezealor AU. Helminth parasites of the gastrointestinal tract of the double-spurred francolin, Francolinus icalcaratus (Linnaeus) in Zaria, Northern Nigeria. The Zoologist. 2006;1(4):39-44.

22. Møller AP, Biard C, Blount JD, Houston DC, Ninni $P$, Saino $N$, Surai PF. Carotenoid-dependent signals: Indicators of foraging efficiency, immunocompetence or detoxification ability? Avian and Poultry Biology Review. 2000;11:137159.

23. Allen PC, Fetterer RH. Recent advances in biology and immunobiology of Eimeria species and in diagnosis and control of infection with these coccidian parasites of poultry. Clinical Microbiology Reviews. 2002;15:58-65.

24. Pap PL, Vágási $\mathrm{Cl}$, Czirják GA, Titilincu A, Pintea A, Osváth $G$, Fülöp A, Barta Z. The effect of coccidians on the condition and immune profile of moulting house sparrows (Passer domesticus). The Auk. 2011;128(2): 330-339.

(c) 2020 Assam et al.; This is an Open Access article distributed under the terms of the Creative Commons Attribution License (http://creativecommons.org/licenses/by/4.0), which permits unrestricted use, distribution, and reproduction in any medium, provided the original work is properly cited.

Peer-review history:

The peer review history for this paper can be accessed here: http://www.sdiarticle4.com/review-history/58378 